\title{
EXAMINING EVERYDAY OUTDOOR PRACTICES IN SUBURBAN PUBLIC SPACE
}

\section{The Case for an Expanded Definition of Care as an Analytical Framework}

\author{
Samantha Biglieri
}

\section{Introduction}

Most urban research takes place in major cities or rural areas, leaving out the difficult task of defining peripheral, suburban areas in theoretical debates on the future of cities (Keil 2018). This has led to a tradition of historically considering the suburban as monolithic, universally 'bad' places, and/or reducing them to caricatures (ibid. 2020). This perspective, however, is changing, with the recognition of suburbanization as a global process and phenomenon, and the realization that the suburbs are hyper-diverse, complex places that deserve study, which focuses on their lived experiences, and upends the centralist bias (ibid. 2018, 2020; Pitter and Lorinc 2016). This changing perspective highlights an important gap-the need for better theorizing and understanding of everyday life for marginalized and vulnerable populations in these suburban areas (Lo et al. 2015).

Understanding everyday practices must take place at the intersections of the socio-spatial, and to think of these ordinary practices as relational. This is following in the footsteps of social scientists beginning with Henri Lefebvre in the 1960s-rejecting conventional views of space as a container-suggesting that people make places and places make people (Lefebvre 1996). This humanist perspective on relational space can also be "reworked and extended in 'other-than-fully conscious' and 'more-than-human' terms" (Andrews and Duff 2019: 123, original emphasis) by post-humanist understandings, which is the approach taken in this chapter. Post-humanist perspectives understand assemblages of embodiments, more-than-human objects (technologies, nature, built environments, etc.), and meaningmaking processes at all scales (from the body to socio-cultural-political constructions) as fluid through time, and key to challenging physical determinism to richly describe everyday life (Andrews and Duff 2019; Cummins et al. 2007; Graham and Healy 1999; Tornaghi 2015). Further insights on post-humanist understandings of place and health ask researchers to (among other things) see place as a temporary collection of socio-spatial relations, constantly in flux; reject the idea of the all-knowing, rational individual; examine habits/ impulses; understand experiences through all senses; and focus on acts as they are happening in context, in relation with human/more-than-human others (Andrews and Duff 2019). 
I argue that careful attention to both these humanist ideas, and their extension through post-humanist orientations, are key to answering the question of how to deeply understand everyday practices. I contend that when combined with using an expanded definition of care as an analytical framework, we can begin to understand the socio-spatial relationalities and assemblages of everyday life at all scales in a way that challenges assumptions about vulnerable individuals, and can reveal inequalities, injustice, and even justice. By drawing on previous empirical research with people living with dementia and their experiences in their suburban neighborhoods in Waterloo, Canada, I expand the examination of care into suburban public spaces (Amin 2012; Rosa 2019). I demonstrate how as an organizing principle, care can get us to see ourselves as interdependent at all scales, and to consider all of humanity vulnerable, with a call to care for others in public spaces. For practitioners, this focus on interdependencies allows us to see the multiplicity of connections and relations that influence everyday practices in public spaces, revealing insights for building more inclusive communities.

\section{Using Care to Examine Everyday Socio-Spatial Relational Life}

We begin with this purposefully broad definition of care, as this definition can offer a "situated engagement with the multiple and complex circumstances producing the need for care (and justice), but they also offer an explanation of how people are operating in the urban to repair our world" (Williams 2017: 825, referring to Tronto 1993):

[Caring can] be viewed as a species activity that includes everything we do to maintain, continue and repair our 'world' so that we can live in it as well as possible. That world includes our bodies, our selves and our environment, all of which we seek to interweave in a complex, life-sustaining web.

(Fisher and Tronto 1990: 40, original emphasis)

This definition comes from a relational ontology and is emotional, particular, embodied, and contextual (Lawson 2008; Williams 2017). In geography, care has been adopted/expanded through scale in diverse ways. For instance, it has encompassed examining close relationships between people in typical locations where 'care' happens (how care relationships are (re)produced between partners through home care, or between professionals and patients within social infrastructures like an institutional facility), examining how people 'care for' the environment (Jones 2019), and at the global scale (how the neoliberalization of professional care work and global migration of care-workers affects their families and those they work for) (Lawson 2008). Care has also been a lens to view everyday practices as acts of selfcare in the urban environment-see the work with Roma women in Europe by Elisabetta Rosa (2019) — and has expanded to describe everyday encounters in public spaces between strangers who "sustain forms of conviviality and kindness" (Imrie and Kullman 2017: 6). Ash Amin (2012:34) calls this an "expanded politics of care" in which the built environment can be an important part and pre-condition for interpersonal relations. Sophie Bowlby (2012) conceives of these interactions in public spaces as occurring across time-space, and discusses three timescales: (1) individual life-course and intergenerational exchange; (2) individual and collective memory; and (3) daily body rhythms. A care perspective encourages researchers to: 
- Move away from the idea of care as asymmetry between the vulnerable person and generosity of the other (Rosa 2019);

- Research the ordinary — what is visible but escapes our attention — and show how it matters (Laugier 2015, cited in Rosa 2019);

- Go beyond individualist notions to see vulnerability as part of all people, and assume collective "responsibility towards the other (near and far, known and unknown)" (Rosa 2019: 199);

- Think of interdependencies (between people and people, places, and objects) and reject the dependent/independent dichotomy;

- Examine both structure and agency, and recognize that they are not as discernable in everyday life; and

- Understand that disability is both embodied and a result of structural factors. A focus on individualism and autonomy fails to accommodate a diversity of embodied experiences.

This perspective allows us to get away from the one-directional question of 'Who cares for whom?' and instead ask 'How do we care?' and interrogate the multiplicity of relations/acts of care between humans and more-than human entities and structures (Rosa 2019). Through asking this question in my previous empirical work with people living with dementia, I found that a care lens can interrogate how people adapt to their existing environments, and (re)make their neighborhoods into a place that is comfortable to them, how they care for themselves and their loved ones through their everyday practices in public space, and how ephemeral encounters with human and more-than-human entities care for them. These findings have allowed me to draw five main insights that using a care lens can help reveal about everyday life in suburban public spaces that will be explored in this chapter. These insights include identifying inaccessible built environments; noticing innovative practices; discovering how people create interdependent networks; examining the power of small encounters; and detailing how spatial practices are shaped by socio-cultural-political structures.

\section{Living with Dementia in Suburban Space}

Dementia refers to a set of symptoms that are caused by a variety of different diseases, the most common being Alzheimer's disease. Dementia symptoms can include getting lost in familiar places; issues with communication and changes in behavior; putting things in the wrong place; impaired depth perception and judgment; as well as short- and long-term memory loss. Most dementia symptoms (and the diseases/conditions that cause them) are progressive, and currently without a cure (WHO 2017). There are a number of misconceptions about people living with dementia, including the assumption that they all live in congregate living facilities. Canadian estimates show that two-thirds of people living with dementia live in the community, in private households with family or alone (Alzheimer Society of Canada 2010). They can be considered marginalized, in the sense that the world around them has been built for the 'normate' - the able-bodied, white, heterosexual, 30-something male (GarlandThompson 1996, cited in Hamraie 2013). Activists who are living with dementia themselves seek to challenge this tendency to build/plan for the 'normate', by referring to dementia as a disability, and stating their demand to have their disabilities met with enablement and respect in society (Houston et al. 2020; Swaffer 2014). Part of challenging this tendency is to 
understand everyday life for people living with dementia in public spaces, thus challenging problematic misconceptions influenced by the stigmatization of these people.

\section{Everyday Built Environments of Care Study}

This chapter draws on a previously conducted case study of seven people living with dementia in the Regional Municipality of Waterloo, Canada (Biglieri 2019). The participants were mostly in their late fifties or early sixties, lived at home in the community, and in a typologically defined car-dependent area (Gordon et al. 2019). ${ }^{1}$ The research methods included seven sit-down introduction interviews asking about where the participant grew up, how they got around in childhood and adulthood, what had changed since diagnosis and what they were nervous about in the future; 13 go-along interviews (Carpiano 2009; Dean et al. 2020); as well as two-week GPS tracking; ${ }^{2}$ and Travel Diary monitoring ${ }^{3}$ for each participant. The interviews were first analyzed using a constructivist grounded theory approach and read through a care lens. Then the findings from the GPS tracking and Travel Diaries were used to supplement a few of the themes (as appropriate) that were generated through the constructivist grounded theory process. ${ }^{4}$

The people living with dementia whom I worked with in this study were beginning to "notice the frictions" between the changes in their everyday lives and the world around them (Fleet 2019). They told me they have good and bad days. Many reflected on the impact that their dementia symptoms had on them, with the most common and prominent change being the loss of their driver's license, shrinking their life space in their car-centric communities. Expanding on findings from Ruth Louise Bartlett and Tula Brannelly (2019), who noted people living with dementia experience a declining sense of how to act in outdoor life, many participants from this study expressed a newfound fear of getting lost in unfamiliar places. Others noticed impaired depth perception, risk analysis, having to be 'on alert', and being easily startled (which did not happen previously). Some described how feeling panicky and losing confidence in oneself makes walking around more difficult and almost prohibitive.

Faced with these frictions and changes, this study on the ordinary outdoor practices (Laugier 2015, cited in Rosa 2019) of people living with dementia demonstrated how when using care as an organizing principle, they (re)make their world to adapt in it, revealing innovative practices. They did this in a number of ways, and their everyday outdoor practices can be conceptualized as a network of relations between themselves, human, and more-thanhuman entities through time (see Figure 9.1). For instance:

- 'Processes of self-care in place, over time': Participants' present-day selves were cared for by their past selves who made the decision to live in the same neighborhood for multiple years, creating familiarity that their present-day selves considered such a support. Self-care in the present included aspects like the avoidance of certain busy, noisy built environments, and caring for future selves encompassed learning how to walk to places and using transit, in addition to making walking a habit to ensure they remember their neighborhoods;

- 'Care interdependence in place': Post-diagnosis, people living with dementia were (re)organizing their newfound interdependent realities with close others. Faced with losing their driver's licenses, the participants in this study discussed how they had built a complex network of individual trips and those where they drew on the help of others 
(drives with friends, visits to family, rides with paratransit services, places of worship, carpooling, etc.). They also discussed the myriad ways that they cared for close others in their neighborhoods; and

- 'Encounter as care': The people living with dementia in this study were being cared for through human and more-than-human encounters in public spaces. The power of interactions with people, animals, little libraries, and gardens were prominent features of the go-along interviews, suggesting it made them feel good.

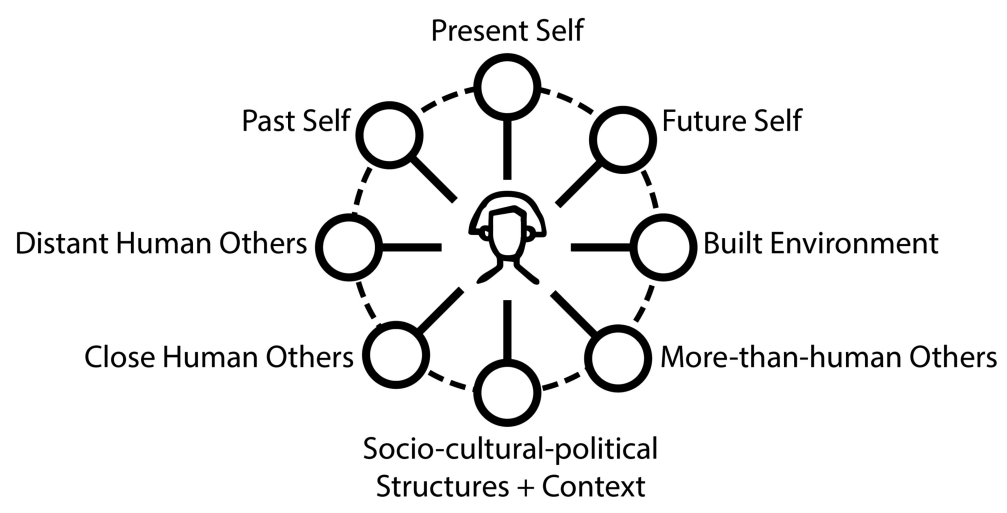

FIGURE 9.1 Mapping out care relations in suburban public space through time. These relations are conceptualizedasinterdependentandconstantlyinteractingwithoneanother,influencingone's perceptions, habits, decisions, and everyday lives. Source: Samantha Biglieri, 2020.

These socio-spatial relational processes were also highly influenced by socio-cultural-political structures (stigmatization of dementia and who 'should' go outside alone) and the built environment (a suburban environment catering to drivers to the detriment of pedestrian experience).

\section{What Can the Care Lens Teach Practitioners?}

I argue that a care lens has much to offer planning, public health, urban design, and community practitioners in suburban neighborhoods, given what it reveals about everyday life in public spaces. Using a care lens allows us to examine everyday socio-spatial relations and practices as acts of care. In the study referenced above, a care lens showed that the unpredictability of dementia makes it difficult to "maintain one's world so they can live in it as well as possible" (Fisher and Tronto 1990: 40). However, we learned that people living with dementia are doing their best in the suburban areas they live in, by (re)making their activity spaces and using new practices to fit their changing needs and abilities. This research, when viewed through a care lens, can give insight into five interrelated, but different aspects of everyday life that could be applied to other research in suburban spaces with marginalized individuals.

\section{Identifying Inaccessible Built Environments}

In their everyday lives, people living with dementia altered their behavior based on the built environment in order to ensure (for themselves) that they do not get stressed out or panicked. 
For instance, they would intentionally not cross busy arterial roads, or avoid them altogether, instead opting for quieter, more familiar residential streets. As one participant said in reference to only going on an arterial street to reach a destination, "I need to get where I am going so I come [...] but it is not my favorite way to walk [...] it is close to so much busy, smelly, traffic" (81-year old female participant, go-along interview, July 2018). Others discussed how much they liked buffer zones between sidewalks and roads (see Figures 9.2, 9.3, and 9.4) and obvious landmarks (like the town's clocktower that served as a visual and soundscape landmark) and complained about a lack of street signage. They all remained within the realm of what they consider 'familiar' to ensure they felt safe. By examining actions and preferences as acts of 'self-care' in space, we can reveal inaccessible urban design and land use policies that restrict the mobility of certain individuals.

\section{Noticing Innovative Practices (to Build On)}

During the go-along interviews, people living with dementia revealed the innovative ways in which they were dealing with their changing abilities and the environments around

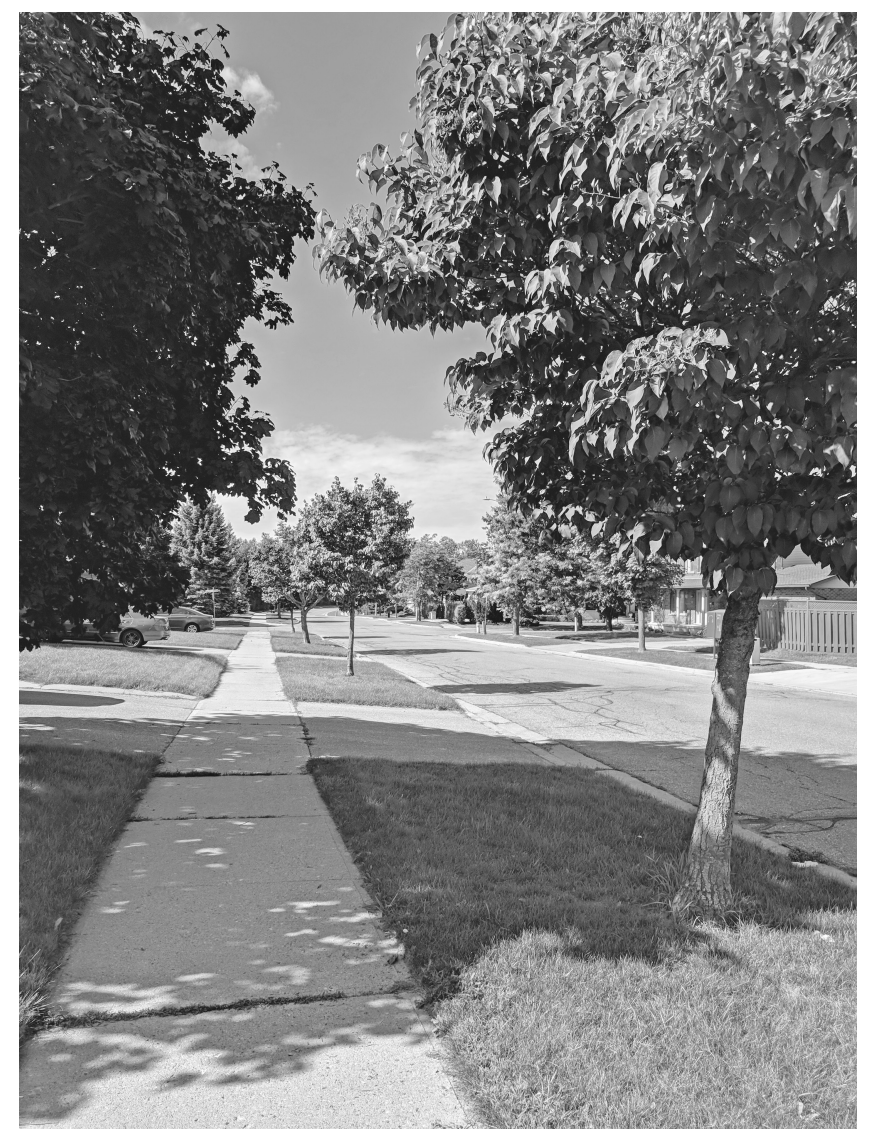

FIGURE 9.2 Examples of perceived comfortable and safe streetscapes for people living with dementia. Source: Samantha Biglieri, 2018. 


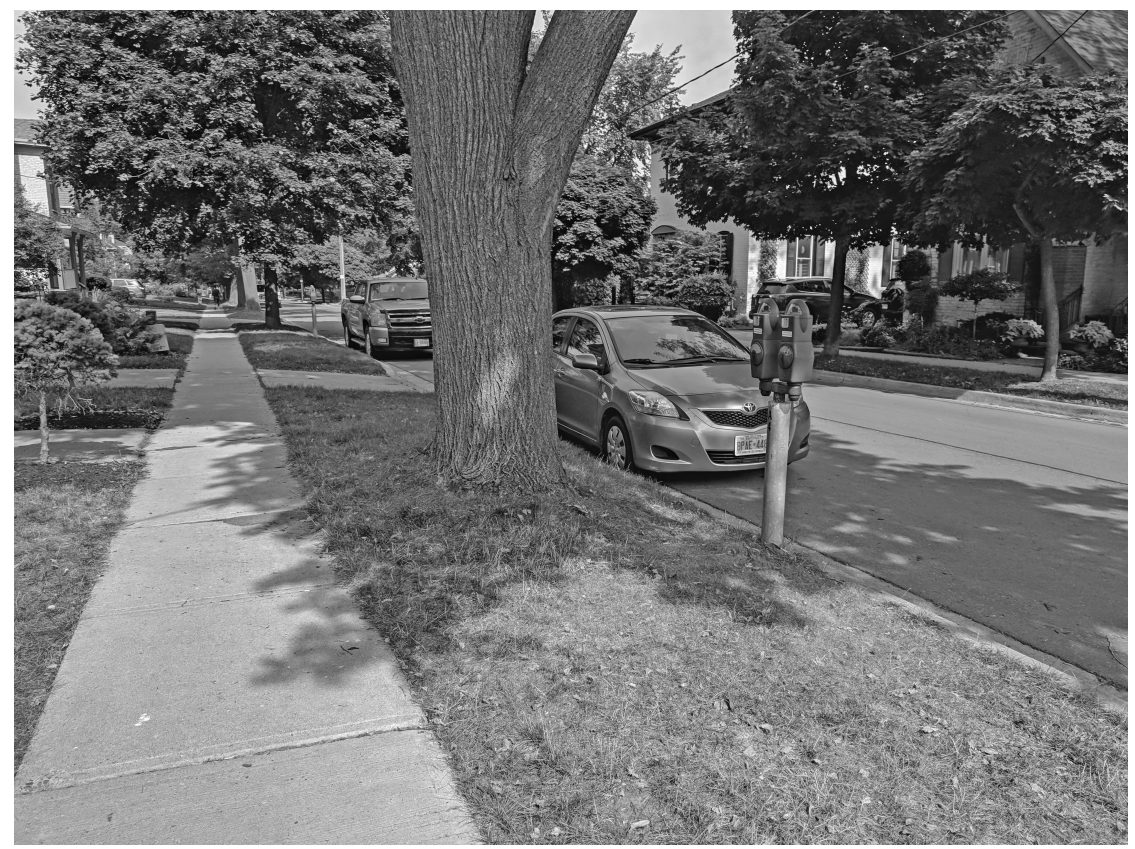

FIGURE 9.3 Examples of perceived comfortable and safe streetscapes for people living with dementia. Source: Samantha Biglieri, 2018.

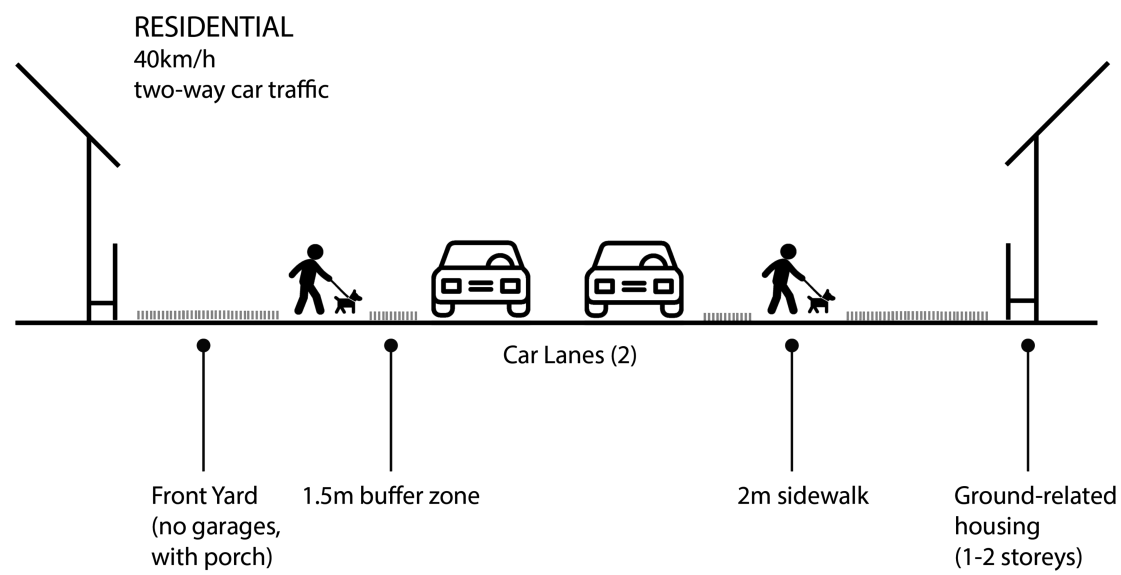

FIGURE 9.4 Example cross-section of comfortable and safe suburban streetscape for people living with dementia. Person icon made by Freepik from www.flaticon.com, car icon made by Kiranshastry from www.flaticon.com. Source: Samantha Biglieri, 2020.

them. For instance, they preferred to cross at medians in the middle of a road, instead of a signalized intersection. They explained that at the signalized intersection, there was just 'too much' going on-cars zooming past them, cars turning left and right, the pedestrian signal, the stoplight for the cars, staying within the painted lines, the signal countdown, and 
other people walking. So instead, they preferred to cross mid-road at the median, where they only had to pay attention to one thing at a time (in this case, one direction of traffic at a time). This experience could serve as a lesson for practitioners to think of the impact of the number of information inputs that people have to negotiate when crossing the street, and how an accumulation of too many sources of information can overwhelm certain individuals to the point that they will not use it, and might lead to them using unexpected and potentially dangerous paths (e.g., jaywalking). Urbanists and planners need to think of these innovative practices revealed through a care lens as something to learn from and build on. For instance-by understanding the reason people living with dementia jaywalk (potentially dangerous behavior) is because the nearest intersection is too far away, or too overwhelming-planners could build more frequent intersections, decrease the number of inputs at an intersection (e.g., simplified, longer pedestrian signals, no right or left turns unless explicit right of way), and/or make the median crossing safer through the use of pedestrian crossing lights for cars.

\section{Discovering How People Create Interdependent Networks}

Often, people living with dementia are framed as dependent. However, a care lens used in this study upended this assumption and revealed they were engaged in caring for others in their everyday practices. This included caring for neighbors by buying their groceries for them, shoveling snow for older neighbors, and running errands for their partners while they are at work. One participant cared for his partner by not veering off his daily walking route, so that the partner would always know where he was, and another promised his sister he would wear reflective gear so that he would be more visible to cars while walking. Further, post-diagnosis, people living with dementia created and relied on a complex interdependent mobility network, made up of walking and public transport trips on their own (independent) and drives from family and friends (dependent). By thinking of mobility as an interdependent network combining independent and dependent trips, you gain a better understanding of lived experience. These interdependent networks might also more realistically indicate barriers to mobility for diverse individuals, and are impacted by the built environment/existing local public transport, and where your support network lives and what their schedules are. The interdependency insight into these complexities could help with local program delivery and building community around shared responsibility for others.

\section{The Power of Small Encounters}

Encounters with human and more-than-human others for people living with dementia made them feel cared for in their neighborhoods. During go-along interviews, all participants said hello to at least one passerby they did not know, commenting on the nice weather, cooing at a baby in a stroller, or talking about the previous night's football game. Others interacted with the built environment and more-than-human others, like rivers, birds, cats, gardens, little libraries, and dogs. After the interactions, they seemed to have more 'pep in their step, suggesting these ephemeral encounters made them feel good. A care lens can reveal the impact of these small encounters on one's sense of inclusion, by getting practitioners to think of these encounters with humans and more-than humans as caring for one another in public space (or not). 


\section{How Spatial Practices Are Affected by Socio-Cultural-Political Structures}

One of the biggest socio-cultural-political structures that affects the everyday outdoor practices of people living with dementia is the ableist stigmatization of dementia itself. It has resulted in societal conceptions of dementia as a tragic, inevitable decline in which a person should disengage from society completely because they are 'not there anymore' (Mitchell et al. 2013; Swaffer 2015). This was evident in the ways in which participants' doctors dictated how they should act in public space. Recommendations ranged from one participant's doctor who prescribed three social and physical activities a week; to another doctor who advised the participant to never go outside again by herself. This prescription from the doctor severely impacted this participant's everyday practices. Her experience demonstrates how socio-cultural-political structures (like the ableist stigmatization of dementia) can be enacted vis-à-vis individuals with power (like doctors) and have problematic consequences. This is an example of the need to address these discourses to not only make people living with dementia feel like they belong in society and to support their inclusion in public spaces, but to enable them to benefit from the physical and psychological well-being benefits of strolling in public space. Thinking about care/non-care relations in public space necessitates a deep discussion and examination of the socio-cultural-political structures that construct these relations themselves. Using a care lens allows practitioners to see these relations in their totality, as opposed to within siloed scales, and might be applicable to other people who face socio-culturalpolitical structural discrimination as well, like racism, ableism, classism, sexism, ageism, and homophobia.

\section{Applying the Care Lens}

Care is an intersectional lens that can indicate to planners and other practitioners how and why people do certain things/take certain routes in public spaces in a holistic manner that takes into account the complexity of everyday life on decision-making. When combined with methods like a go-along interview which focuses on sensory experiences and understanding behavior as it is happening in context, including noticing habits, impulses, and reactions (a post-humanist orientation), as well as investigating the narrative of their neighborhood by asking individuals about why they go where they go, what they liked or disliked (a humanistic orientation) - these insights can then be used to inform design processes for more inclusive built environments. For instance, examining mobility through the different aspects mentioned in Figure 9.1 could reveal important information for practitioners, especially when working with more marginalized groups. For instance, by examining what people do for 'self-care' in space, one might discover that Person A rides a bike to work because it is good for their health and is cheaper than alternatives ('past, present, and future selves'), but that they also only select routes with protected bike lanes because they are scared of travelling on other road types ('present selves' and 'built environment'). Examining how their movement is shaped by their 'relationships with close others' could tell us how picking up children from school or volunteering in the morning requires them to use certain modes. Lastly, by understanding 'relations with more distant others' (e.g., greeting people on the street or waving at neighbors) and 'more-than-human others' (e.g., choosing to walk through the park to see the birds), we can reveal how or if people feel connected to and safe in their community. By looking at mobility in this manner, it is possible to reveal 'built environment' inequalities as experienced by different populations, and understand the influence of and 'socio-cultural-political structures' on 
these experienced inequalities overall (for instance, understanding how ableism and ageism influence the design of public spaces, which are not value neutral). Practitioners can use this framework to address these issues to build an inclusive city.

\section{Conclusion}

A care lens is an effective way to understand socio-spatial, relational everyday life in suburban public spaces for people living with dementia. It adds to research disputing that everyday life in the suburbs is monolithic and timeless by showing the dynamic interplay of impairment, embodiment, and socio-cultural-political structural barriers over time (Keil 2020). I argue that this care lens should be extended to studying everyday life for vulnerable populations in suburban areas, as it brings to light a multitude of practices that highlight the complexity of one's route choices and activity space, and how that is influenced by personal history and relationships with human and more-than-human others through time. For people living with dementia, using a care lens to understand their everyday innovative practices challenges their stigmatization, revealing their joy of going outdoors and their ability to adapt their practices to enable themselves to do so. Further, the care lens disrupts the in/dependent dichotomy by establishing their experiences in public space as interdependent, while still identifying inequalities in access. Such a focus begins to reveal the unjust structural and spatialized impacts of stigmatization of dementia due to ableism and ageism. A care lens speaks to the importance of understanding people living with dementia and people generally-as multifaceted individuals who are simultaneously engaged in caring for or being cared for by themselves, family/friends, others - and the built environment. It paints a fuller picture of the complexities of everyday life and has the potential to provide insight into in/justice in suburban areas. A care lens has the capacity to enact what Miriam Williams (2017: 821) refers to as "care-full justice": combining an examination of grassroots responses to injustice (how people care for themselves and their communities in time-space) with normalized principles of justice in space (the right to access the city). Furthermore, this lens fits well with recent calls in planning theory for compassionate and restorative planning (Lyles and Swearingen White 2019; Schweitzer 2016). It is capable of capturing the nuance required to understand suburban areas as a site of everyday struggle (Keil 2018) with an increasingly hyper-diverse population who lives in these places (Patel et al.2018).

To support people living with dementia in public spaces, as a society we need to challenge the discourse of independence by focusing on mutual interdependence in our practice, policies, and understandings of relational public space. We all rely on networks of complex relationships through time with ourselves, our families and friends, neighbors, strangers, flora and fauna, objects, technologies, public services and programs, as well as the built environment to live our everyday lives. Being able to access one's neighborhood is a right, and it is vital to work with marginalized individuals to identify inequalities and barriers to access as injustice, as well as augmenting their innovative practices and care relations to build more inclusive neighborhoods from the ground up.

\section{Notes}

1 The official names of the typologies that participants lived in were 'Auto-Suburb' and 'Exurban' areas and were defined using the Transportation Method with 2016 Canadian Census Data (Gordon et al. 2019). 
2 Participants wore a Columbus V-900 GPS Data Logger for a period of two weeks, plugging it in every evening. In addition to GPS coordinates and time, this tracker was able to record how fast the participant was moving (an indication of mode choice).

3 The Travel Diary asked participants to fill in the following information every time they left their home: What time did you leave? When did you return? Where did you go (and what did you do)? Who were you with? How did you get there? Was there anything you noticed that bothered you?

4 For instance, one of the themes discusses the interdependent network of travelling alone and drawing on the help of others. The findings were supplemented by the GPS tracking and Travel Diaries, as we were able to separate out these different kinds of trips and to illustrate the impact of seeing mobility as an interdependent network.

\section{References}

Alzheimer Society of Canada (2010) Rising Tide: The Impact of Dementia on Canadian Society [Online]. Available at https://alzheimer.ca/sites/default/files/files/national/advocacy/asc_rising_tide_full _report_e.pdf [Accessed 28 January 2020].

Amin, A. (2012) Land of Strangers. Cambridge: Polity Press.

Andrews, G.J. and Duff, C. (2019) Matter Beginning to Matter: On Posthumanist Understandings of the Vital Emergence of Health. Social Science and Medicine 226: 123-134.

Bartlett, R. and Brannelly, T. (2019) On Being Outdoors: How People with Dementia Experience and Deal with Vulnerabilities. Social Science and Medicine 235(112336). https://doi.org/10.1016/j.socs cimed.2019.05.041.

Biglieri, S. (2019) Planning Dementia-Inclusive Suburban Neighbourhoods. Doctoral Thesis, University of Waterloo.

Bowlby, S. (2012) Recognising the Time-Space Dimensions of Care: Caringscapes and Carescapes. Environment and Planning A: Economy and Space 44(9): 2101-2118.

Carpiano, R.M. (2009) Come Take a Walk with Me: The "Go-Along" Interview as a Novel Method for Studying the Implications of Place for Health and Well-Being. Health and Place 15(1): 263-272.

Cummins, S., Curtis, S., Diez-Roux, A.V. and Macintyre, S. (2007) Understanding and Representing "Place" in Health Research: A Relational Approach. Social Science and Medicine 65(9): 1825-1838.

Dean, J., Biglieri, S., Drescher, M., Garnett, A., Glover, T. and Casello, J. (2020) Thinking Relationally about Built Environments and Walkability: A Study of Adult Walking Behavior in Waterloo, Ontario. Health and Place 64(102352). https://doi.org/10.1016/j.healthplace.2020.102352.

Fisher, B. and Tronto, J.C. (1990) Toward a Feminist Theory of Caring. In E.K. Abel and M.K. Nelson (eds.) Circles of Care:Work and Identity in Women's Lives. Albany: State University of New York Press, pp. 35-62.

Fleet, C. (2019) Digital Frictions in Nonvisual Accessibility and the Built Environment. Paper presented at the \#A11 IIRL Conference, \#A11yIRL, Toronto, 23 October.

Garland-Thomson, R. (1996) Extraordinary Bodies: Figuring Disability in American Culture and Literature. New York: Columbia University Press.

Gordon, D., Willms, C. and Hindrichs, L. (2019) Kitchener-Waterloo-Cambridge:Transportation T9 Method [Online]. Queen's School of Urban and Regional Planning. Available at http://canadiansuburbs.ca/ files/Kitchener_T9_2016.pdf [Accessed 16 October 2019].

Graham, S. and Healey, P. (1999) Relational Concepts of Space and Place: Issues for Planning Theory and Practice. European Planning Studies 7(5): 623-646.

Hamraie, A. (2013) Designing Collective Access: A Feminist Disability Theory of Universal Design. Disability Studies Quarterly 33(4). http://dx.doi.org/10.18061/dsq.v33i4.3871.

Houston, A., Mitchell, W., Ryan, K., Hullah, N., Hitchmough, P., Dunne, T., Edwards, B., Marshall, M., Christie, J. and Cunningham, C. (2020) Accessible Design and Dementia: A Neglected Space in the Equality Debate. Dementia 19(1): 83-94.

Imrie, R. and Kullman, K. (2017) Designing with Care and Caring with Design. In C. Bates, R. Imrie and K. Kullman (eds.) Care and Design: Bodies, Buildings, Cities. Oxford:Wiley-Blackwell, pp. 1-15. 
Jones, R. (2019) Really Shit Work? Bodily Becoming and the Capacity to Care for the Urban Forest. Social and Cultural Geography 20(5): 630-648.

Keil, R. (2018) Suburban Planet: Making the World Urban from the Outside In. Cambridge: Polity Press.

Keil, R. (2020) After Suburbia: Research and Action in the Suburban Century. Urban Geography 41(1): $1-20$.

Laugier, S. (2015) La vulnérabilité des formes de vie. Raisons politiques 57(1): 65-80.

Lawson,V. (2008) Geographies of Care and Responsibility. Annals of the Association of American Geographers 97(1): $1-11$.

Lefebvre, H. (1996) Writings on Cities. Oxford: Blackwell.

Lo, P.C.L., Anisef, P., Wang, S., Preston, V.A., Basu, R. and Wang, S. (2015) Social Infrastructure and Vulnerability in the Suburbs. Toronto: University of Toronto Press.

Lyles, W. and Swearingen White, S. (2019) Who Cares? Arnstein's Ladder, the Emotional Paradox of Public Engagement, and (Re)Imagining Planning as Caring. Journal of the American Planning Association 85(3): 287-300.

Mitchell, G., Dupuis, S. and Kontos, P. (2013) Dementia Discourse: From Imposed Suffering to Knowing Other-Wise. Journal of Applied Hermeneutics 2013(5). https://doi.org/10.11575/jah.v0i2.53220.

Patel, A., Regier, K., Wilson, K., Ghassemi, E. and Dean, J. (2018) Beyond the Cosmopolis: Sustaining Hyper-Diversity in the Suburbs of Peel Region, Ontario. Urban Planning 3(4): 38-49.

Pitter, J. and Lorinc, J. (eds.) (2016) Subdivided: City-Building in an Age of Hyper Diversity. Toronto: Coach House Books.

Rosa, E. (2019) Why Self-Care Matters for Roma People and Beyond: Vulnerability and the (Un-) Making of Water and Sanitation Infrastructure at the Margins of the City. Geoforum 101: 192-201.

Schweitzer, L. (2016) Restorative Planning Ethics:The Therapeutic Imagination and Planning in Public Institutions. Planning Theory 15(2): 130-144.

Swaffer, K. (2014) Dementia: Stigma, Language, and Dementia-Friendly. Dementia 13(6): 709-716.

Swaffer, K. (2015) Dementia and Prescribed Disengagement ${ }^{\mathrm{TM}}$. Dementia 14(1): 3-6.

Tornaghi, C. (2015) The Relational Ontology of Public Space and Action-Oriented Pedagogy in Action: Dilemmas of Professional Ethics and Social Justice. In C. Tornaghi and S. Knierbein (eds.) Public Space and Relational Perspectives: New Challenges for Architecture and Planning. New York: Routledge, pp. $17-42$.

Tronto, J.C. (1993) Moral Boundaries: A Political Argument for an Ethic of Care. New York: Routledge.

Williams, M.J. (2017) Care-Full Justice in the City. Antipode 49(3): 821-839.

World Health Organization (WHO) (2017) Global Action Plan on the Public Health Response to Dementia 2017-2025. Geneva:World Health Organization. 
$\because$ Taylor \& Francis Taylor \& Francis Group http://taylorandfrancis.com 